\title{
A protective personal factor against disability and dependence in the elderly: an ordinal regression analysis with nine geographically-defined samples from Spain
}

Javier Virues-Ortega ${ }^{1,2^{*}}$ (D), Saturio Vega ${ }^{3}$, Manuel Seijo-Martinez ${ }^{4}$, Pedro Saz ${ }^{5}$, Fernanda Rodriguez ${ }^{6}$, Angel Rodriguez-Laso ${ }^{7}$, Susana Perez de las Heras ${ }^{8}$, Raimundo Mateos ${ }^{9}$, Pablo Martinez-Martin ${ }^{1}$, Ignacio Mahillo-Fernandez ${ }^{1}$, Josep Garre-Olmo ${ }^{10}$, Jordi Gascon ${ }^{11}$, Francisco Jose Garcia-Garcia ${ }^{12}$, Manuel Fernandez-Martinez ${ }^{13}$, Felix Bermejo-Pareja ${ }^{14}$, Alberto Bergareche ${ }^{15,16}$, Julian Benito-Leon ${ }^{14}$, Jesus de Pedro-Cuesta ${ }^{1}$ and on behalf of the Spanish Epidemiological Studies on Ageing Group

\begin{abstract}
Background: Sense of Coherence (SOC) is defined as a tendency to perceive life experiences as comprehensible, manageable and meaningful. The construct is split in three major domains: Comprehensibility, Manageability, and Meaningfulness. SOC has been associated with successful coping strategies in the face of illness and traumatic events and is a predictor of self-reported and objective health in a variety of contexts. In the present study we aim to evaluate the association of SOC with disability and dependence in Spanish elders.

Methods: A total of 377 participants aged 75 years or over from nine locations across Spain participated in the study (Mean age: 80.9 years; $65.3 \%$ women). SOC levels were considered independent variables in two ordinal logistic models on disability and dependence, respectively. Disability was established with the World health Organization-Disability Assessment Schedule 2.0 (36-item version), while dependence was measured with the Extended Katz Index on personal and instrumental activities of daily living. The models included personal (sex, age, social contacts, availability of an intimate confidant), environmental (municipality size, access to social resources) and health-related covariates (morbidity).
\end{abstract}

Results: High Meaningfulness was a strong protective factor against both disability (Odds Ratio [OR] = 0.50; 95\% Confidence Interval $[\mathrm{Cl}]=0.29-0.87)$ and dependence $(\mathrm{OR}=0.33 ; 95 \% \mathrm{Cl}=0.19-0.58)$ while moderate and high Comprehensibility was protective for disability $(\mathrm{OR}=0.40 ; 95 \% \mathrm{Cl}=0.22-0.70$ and $\mathrm{OR}=0.39 ; 95 \% \mathrm{Cl}=0.21-0.74)$, but not for dependence. Easy access to social and health resources was also highly protective against both disability and dependence.

Conclusions: Our results are consistent with the view that high levels of SOC are protective against disability and dependence in the elderly. Elderly individuals with limited access to social and health resources and with low SOC may be a group at risk for dependence and disability in Spain.

Keywords: Sense of coherence, Disability, Dependence, Katz index, WHODAS 2.0

\footnotetext{
* Correspondence: j.virues-ortega@auckland.ac.nz

${ }^{1}$ National Centre for Epidemiology and CIBERNED, Carlos III Institute of Health, Madrid, Spain

${ }^{2}$ School of Psychology, The University of Auckland, Room 335B Level 3 Bldg

301 Science Centre 23 Symonds St Private Bag 92019, Auckland 1010, New

Zealand

Full list of author information is available at the end of the article
} 


\section{Background}

There seems to be a growing interest in the literature in understanding how personal factors impact chronic diseases and disability [1]. Greater attention has been devoted to behavioral risk factors (e.g., anger, type A behavior pattern), as opposed to protective behavioral factors. Among the latter, resilience, hardiness and sense of coherence (SOC) have been associated with selfreported health, sickness recovery, and protection against sickness [2]. Therefore, protective behavioral factors are heuristically valuable constructs to approach the connection between health and behavior [3].

A. Antonovsky developed an approach to the origin and maintenance of health based on personal cognitive factors and defined SOC as the key of his theory. Sense of coherence is defined as "a global orientation that expresses the extent to which one has a pervasive, enduring though dynamic feeling of confidence that (a) the stimuli deriving from one's internal and external environments in the course of living are structured, predictable, and explicable (comprehensibility); (b) the resources are available to one to meet the demands posed by these stimuli (manageability); and (c) these demands are challenges, worthy of investment and engagement (meaningfulness)" [4].

Over the last decades hundreds of empirical studies have related SOC to health variables such as psychological well being, adaptive coping strategies, social support as well as self-reported and clinically-assessed physical health [5-7]. Very few studies, however, have focused on the relationship between a strong SOC and specific health dimensions in elderly populations such as self-reported health and functional status. Schneider et al. [8] reported that SOC exerts an independent positive influence towards self-reported health among a sample of geriatric patients. Another study showed that individuals with stronger SOC kept their functional status for longer relative to individuals with weaker SOC [9]. Read et al. [10] reported that SOC was significantly associated with physical, social and mental health in a probabilistic sample of 65-69 year-old participants. Moreover, SOC has been linked to adherence to rehabilitation programs among elder patients living at home [11], and with an approximately $30 \%$ reduction in mortality, including mortality due to cardiovascular disease and cancer [12].

The International Classification of Functioning, Disability and Health (ICF) provides a general framework to conceptualize and classify complex interactions of environmental and personal factors over functioning and disability [13]. While there is a growing repertoire for the assessment and interpretation of factors pertaining to physical health and social behavior, both in terms of standardized instruments and disease-specific core sets of assessment areas [14], behavioral factors are still ill-informed as far as evaluation tools and outcome-specific classifications [15]. Thus, exploring SOC-specific disability patterns may be highly informative for the purposes of care and health services planning. Similar evidence has been reported for socio-demographic variables, which have been found predictive of different long-term functional outcomes [16]. A valuable step toward this aim would be to examine the functional relationship between SOC and disability with methods consistent with the ICF framework.

The purpose of this study was to quantify the relationship of SOC domains along with selected social and environmental factors over disability and dependence. Disability and dependence levels were estimated by means of the World Health Organization Disability Assessment Schedule [17] and the Extended Katz Index of dependence [18], respectively. We hypothesize that relatively high scores in SOC domains will be associated with lower levels of disability and dependence in the people older than 75 .

\section{Methods \\ Study sample}

This report is part of a study on aging concerned with physical and mental health, social participation, quality of life and socio-demographic aspects in people older than 75 in Spain. The sample was composed of nine probabilistic and geographically-defined sub-samples from different locations of Central and Northern Spain. Recruitment and data collection took place between June 2005 through December 2005. We recruited surviving participants from previous dementia prevalence studies conducted in Spain [19]. Participants should be aged 75 or older, have an score in the MMSE > 23, and should not have a clinical history of dementia [20], and have usable data in all predictive and outcome variables. Further details on the sampling method and the sample composition have been made available elsewhere [19]. From an original study sample of 546 participants, only participants with computable SOC, disability and dependence data (69.0\%) were included in the present study. Responding to the questionnaire measuring SOC was considered voluntary. A total of 433 individuals were aged above 75 and had an MMSE > 23 [19]. Among these, 56 individuals were excluded due to a history of neurological disease. A total of 377 individuals (mean age: 80.9; 65.3\% women) had complete datasets for the purposes of the current analysis and met all inclusion criteria. The health-related and socio-demographic characteristics of the study sample are shown in Table 1. Detailed reports on dementia and disability prevalence as well as to disability-associated health conditions in the 546 participants have been reported elsewhere $[19,21,22]$. The dataset upon which the current analysis is based is available upon request. 
Table 1 Socio-demographic characteristics and morbidity $(n=377)$

\begin{tabular}{|c|c|}
\hline & Percent (Number) \\
\hline \multicolumn{2}{|l|}{ Age } \\
\hline \multicolumn{2}{|l|}{$75-79$} \\
\hline Women & $30.5(115)$ \\
\hline Men & $16.2(61)$ \\
\hline \multicolumn{2}{|l|}{$80-84$} \\
\hline Women & $16.5(62)$ \\
\hline Men & $11.4(43)$ \\
\hline \multicolumn{2}{|l|}{$\geq 85$} \\
\hline Women & $18.3(69)$ \\
\hline Men & $7.2(27)$ \\
\hline \multicolumn{2}{|l|}{ Self-reported social class } \\
\hline Low & $9.3(35)$ \\
\hline Middle-low & $27.3(103)$ \\
\hline Middle & $52.8(199)$ \\
\hline Middle-high & $10.6(40)$ \\
\hline \multicolumn{2}{|l|}{ Level of instruction } \\
\hline Illiterate & $9.3(35)$ \\
\hline Primary incomplete & $40.9(154)$ \\
\hline Primary complete & $32.1(121)$ \\
\hline Some secondary or higher & $17.8(67)$ \\
\hline \multicolumn{2}{|l|}{ Morbidity (ICD 10 codes) } \\
\hline Mental and behavioral (F00-F99) & $26.3(99)$ \\
\hline Neurological including stroke (G00-G99, 160-169) & $14.1(53)$ \\
\hline Cardiovascular (100-152, 170-199) & $67.9(256)$ \\
\hline Eye $(\mathrm{H} 00-\mathrm{H} 59)$ & $37.9(143)$ \\
\hline Musculoskeletal and injuries (M00-M99; S00-S9) & $48.8(184)$ \\
\hline
\end{tabular}

\section{Procedure}

Data was derived from structured interviews administered during two successive visits to the individual's home. The first visit covered objective and self-reported aspects of health. It was carried out by a licensed physician trained in neurology, psychiatry or geriatrics (average visit duration: $1.5 \mathrm{~h}$ ). The second visit was scheduled within the two-week period following the first (original data collection questionnaires have been provided as Additional file 1). This visit focused on self-reported aspects of functioning and disability in addition to psychological and social factors and was conducted by a purposely trained health professional whether physician, nurse or psychologist (average visit duration: $1 \mathrm{~h}$ ). All variables reported here, with the exception of inclusion criteria and morbidity, were collected during the second interview. The assessments relevant to this study are described below.

\section{Antonovsky's sense of coherence (SOC)}

The Orientation to Life Questionnaire (OLQ-13) consists of 13 items covering the three domains of the SOC construct: meaningfulness (score range: 4-28), comprehensibility (score range: 5-35), manageability (score range: 4-28) [4]. The items are scored over a seven-point Likert scale (e.g., $1=$ never, $7=$ always). Negatively-worded items are reverse coded (items 1, 2, 3, 7, 10). Higher scores indicate higher levels in either of the three SOC domains. The scale has shown appropriate internal consistency and high construct and cross-cultural validity [23]. The OLQ-13 has been adapted to the Spanish elderly population [24] The three domains of the scale were scored separately for all analyses in this study owing to the empirical evidence supporting the multidimensional nature of the construct $[9,24]$.

\section{World health organization disability assessment schedule (WHO-DAS-II)}

This is a self-reported 36-item questionnaire covering six disability domains: Participation in Society, Life Activities, Getting Along with Others, Self-Care, Getting Around and Understanding and Communication. Items are answered over a 5-point Likert scale depending on the difficulty of the participant performing a given activity over the last 30 days (1: None; 5: Extreme). Score per domain and total questionnaire score range from 0 to 100 with higher scores indicating higher disability. Life activities domain was omitted in those individuals with no household duties assigned. In addition, item D4.5 on sexual relationships was excluded from the total score computation as $47.1 \%$ of participants declined to answer. Items on work performance were also omitted as all participants were retired. WHODAS 2.0 total score was transformed into disability categories according to ICF disability levels established over a 100-point scale [13]: No problem (0-4\%), Mild problem (5-24\%), Moderate problem (25-49\%), Severe problem (50-95\%), Extreme problem (95-100\%). Table 2 presents selected characteristics of this instrument.

\section{Katz extended index of dependence in activities of daily living (extended Katz index)}

The Extended Katz Index is a 11-item measure assessing dependence (need of help). It covers six personal basic activities of daily living (BADL) (bathing, dressing, toileting, transferring, continence, and feeding) and five instrumental activities of daily living (IADL) (shopping, cleaning, transportation, washing, and cooking) $[25,26]$. Items are scored over a 3-point scale: independent, in case the individual can carry out the skill without support; partly dependent, if the individual is able to complete the activity with help; and dependent, when the individual is not able to perform the skill even with help from others. 
Table 2 Characteristics of WHODAS 2.0 and the extended Katz index

\begin{tabular}{|c|c|c|}
\hline & WHO-DAS II & Extended Katz index \\
\hline Selected validation & Ustün et al. [17] & Asberg\&Sonn [18] \\
\hline Target construct & Self-reported disability & Objective dependence in activities of daily living \\
\hline Domains & $\begin{array}{l}\text { Understanding and communication; } \\
\text { Getting around; Self-care; Getting along } \\
\text { with others; Life activities; Participation } \\
\text { in society }\end{array}$ & $\begin{array}{l}\text { Personal activities of daily living (bathing, dressing, } \\
\text { toileting, transferring, continence, feeding); } \\
\text { Instrumental activities of daily living (shopping, } \\
\text { cleaning, transportation, washing, cooking) }\end{array}$ \\
\hline Number of items & 32 & 11 \\
\hline Response levels & $\begin{array}{l}\text { No difficulty; mild difficulty; moderate } \\
\text { difficulty; severe difficulty; extreme } \\
\text { difficulty/cannot do it }\end{array}$ & Independent; partly dependent; dependent \\
\hline Score range & $0-100$ & Rationally defined dependence levels \\
\hline Outcome levels in the present study & $\begin{array}{l}\text { No problems (0-4); Mild disability (5-24); } \\
\text { Moderate disability ( } 25-49) ; \text { Severe disability } \\
\text { (50-95); Extreme disability (96-100) }\end{array}$ & $\begin{array}{l}\text { Independent, Dependent in instrumental activities } \\
\text { of daily living; dependent in personal activities of } \\
\text { daily living }\end{array}$ \\
\hline
\end{tabular}

Note. WHODAS 2.0 items on work performance were not used in this study

Scale scores follow a cumulative structure [27]. Descriptive features of the Extended Katz Index are presented in Table 2.

\section{Social support}

Participants' structural social support was explored through the median frequency of personal contacts with children, extended family and friends in a 5-point Likert scale (1: never; 5 : daily contacts). In addition, the availability of an intimate confidant was recorded as an index of emotional social support.

\section{Accessibility to social and health resources}

This variable was measured as the median accessibility over a 5-point scale (1: very easy access; 5 : very difficult access) to six social resources: health center/medical attention, public transportation, public leisure resources (garden, park), shops, social clubs/cultural resources, and religious services.

\section{Municipality size}

The number of inhabitants of the population where individuals were de facto residents were recorded and coded according to the census and categories of the Spanish National Institute of Statistics: Rural-Intermediate (1-10,000 inhabitants), and Urban (>10,000 inhabitants).

\section{Morbidity}

Morbidity was measured as the sum of current medical conditions. Medical conditions were surveyed through a checklist of 51 diseases prevalent in the elderly. Additional conditions not identified in the checklist were also recorded (ICD-10 codes specified a posteriori). The presence of medical conditions was established on the basis of primary care medical records, other medical records provided by the examinee, physical examination, and self- and proxy-reported conditions. This section was administered by a licensed physician and was later supervised by a senior physician. Diagnoses of those at chronic care facilities, nursing homes and psychiatric hospitals were informed by medical records and medical staff at those sites. Diagnosis of dementia and dementia subtypes were conducted by two independent licensed neurologists.

\section{Statistical analysis}

Ordinal logistical regression was used to study the effect of multiple independent variables over disability and dependence. International Classification of Functioning disability categories based on WHO-DAS-II scores, and dependence levels based on Extended Katz Index were considered as separate dependent variables.

Ordinal regression generates a single odd ratio for all ordinal levels within a dependent variable. Thus, the current analysis offsets the need to specify an interval within the target dependent variable for the purposes of case definition. The ordinal intervals for disability were defined following the ICF severity categories: No problem (NP); Mild disability (MILD); Moderate, severe and extreme disability (MO/SE/EX). Fewer individuals were allocated to the three highest ICF disability category, which motivated these three categories to be amalgamated into the MO/SE/EX category. We defined three ordinal intervals for dependence: independent (no dependence in either instrumental or personal ADL), IADL dependent (dependent in one or more IADL but independent in personal ADL), and ADL dependent (dependent in one or more ADL).

Associations between predictive factors and the outcome variables were expressed as odds ratios (OR) and confidence interval $(95 \% \mathrm{CI})$. The criterion for statistical significance was set at $5 \%$. In order to obtain relatively 
symmetric disability levels, moderate, severe and extreme, ICF disability categories were collapsed. Tests for proportional odds were performed to check the homogeneity of the effects across adjacent categories of the dependent variables.

In order to provide a highly specific characterization of the association between SOC, and disability and dependence, scores of Comprehensibility, Manageability, and Meaningfulness were introduced into the model as independent predictors in two separate models, one for of the outcomes. Low, mid, and high levels of Comprehensibility, Manageability, and Meaningfulness scores were established by tertiles using the interval defined by the range between the lowest score and tertile 1 as the reference category. While there is no widely accepted cut-off points for SOC domain levels [23, 28], the current approach is a conservative in that it is purely based on scores distribution. Owing to the size of our sample, it is unlikely that the current approach would exclude any socially valid level of a particular SOC domain. In order to provide a multi-faceted approach to disability in line with the conceptual basis provided by the ICF system, we introduced selected social (social network, availability of confidant), and environmental variables (access to social resources, municipality size), whose influence on disability is well documented $[1,13,15]$. Finally, for control purposes both models were adjusted for age, sex and morbidity (number of ICD-10 diagnoses).

\section{Results}

Counts of participants for each of the ordinal intervals within each of the dependent variables in the analyses are presented in Tables 3 . Table 4 summarizes the final ordinal logistic regression models for disability (WHO-DAS II) and dependence (Extended Katz Index). Age, sex and morbidity were non-significant for all analyses with the exception of sex for disability. Specifically, men were more likely to be at a higher disability level $(\mathrm{OR}=2.01,95 \% \mathrm{CI}$ 1.28-3.17). Odd proportional tests were non-significant for the two models, suggesting that effects were proportional across the categories of the outcome variables.

Mid and high Comprehensibility levels were highly protective against disability and dependence $(\mathrm{OR}=0.40$, 95\% CI 0.22-0.70; OR $=0.39,95 \%$ CI 0.21-0.74). High Meaningfulness was also highly protective for both disability and dependence $(\mathrm{OR}=0.33,95 \%$ CI $0.19-0.58$; $\mathrm{OR}=0.50,95 \%$ CI 0.29-0.87; see also Fig. 1).

The frequency of social contacts remained a nonsignificant protective predictor for disability and dependence. The availability of an intimate confidant demonstrated a significant protective effect against disability $(\mathrm{OR}=0.56,95 \% \mathrm{CI} 0.31-1.01)$. Access to social resources showed a dose-dependent protective effect against both disability and dependence $(\mathrm{OR}=0.18-0.04$;
Table 3 Distribution of participants across predictors and outcome levels



Notes. NP No problem, MILD Mild disability, MO/SE/EX Moderate, severe and extreme disability, IND Independent in personal and instrumental activities of daily living, IALD Dependent in one or more instrumental activity of daily living only, PADL Dependent in one or more personal activity of daily living

$\mathrm{OR}=0.14-0.03$; see Table 4). Living in municipalities with 10,000 inhabitants or more was a protective factor against disability as established by WHO-DAS-II (OR $=0.50$, 95\% CI 0.30-0.84), whereas it was a risk factor for 
Table 4 Summary of ordinal logistic regression analyses for disability and dependence

\begin{tabular}{|c|c|c|c|c|c|c|}
\hline & \multicolumn{3}{|c|}{ WHODAS $2.0(n=377)$} & \multicolumn{3}{|c|}{ Extended Katz index $(n=377)$} \\
\hline & $\mathrm{OR}$ & $95 \% \mathrm{Cl}$ & $p$ & $\mathrm{OR}$ & $95 \% \mathrm{Cl}$ & $p$ \\
\hline \multicolumn{7}{|l|}{ Target predictors } \\
\hline \multicolumn{7}{|l|}{ Comprehensibility (Low) } \\
\hline Mid & 0.40 & $0.22-0.70$ & 0.002 & 0.82 & $0.47-1.44$ & ns \\
\hline High & 0.39 & $0.21-0.74$ & 0.004 & 0.79 & $0.43-1.47$ & ns \\
\hline \multicolumn{7}{|l|}{ Manageability (Low) } \\
\hline Mid & 1.30 & $0.72-2.36$ & ns & 1.95 & $1.09-3.51$ & 0.025 \\
\hline High & 0.76 & $0.40-1.44$ & ns & 1.31 & $0.70-2.46$ & ns \\
\hline \multicolumn{7}{|l|}{ Meaningfulness (Low) } \\
\hline Mid & 0.63 & $0.36-1.10$ & ns & 0.88 & $0.50-1.53$ & ns \\
\hline High & 0.33 & $0.19-0.58$ & 0.000 & 0.50 & $0.29-0.87$ & 0.014 \\
\hline \multicolumn{7}{|l|}{ Social factors } \\
\hline \multicolumn{7}{|c|}{ Availability of confidant (No) } \\
\hline Yes & 0.56 & $0.31-1.01$ & 0.054 & 0.87 & $0.49-1.53$ & ns \\
\hline \multicolumn{7}{|c|}{ Social contacts (Once a month or less) } \\
\hline Biweekly & 1.12 & $0.54-2.31$ & ns & 1.09 & $0.54-2.19$ & ns \\
\hline Weekly & 0.99 & $0.53-1.88$ & ns & 0.78 & $0.42-1.45$ & ns \\
\hline Everyday & 0.70 & $0.36-1.36$ & ns & 0.70 & $0.37-1.33$ & ns \\
\hline \multicolumn{7}{|l|}{ Environmental factors } \\
\hline \multicolumn{7}{|c|}{ Social resources accessibility (Very difficult) } \\
\hline Difficult & 1.44 & $0.30-6.91$ & ns & 0.23 & $0.06-0.86$ & 0.029 \\
\hline Not difficult nor easy & 0.18 & $0.04-0.84$ & 0.029 & 0.14 & $0.04-0.56$ & 0.006 \\
\hline Easy & 0.06 & $0.02-0.20$ & 0.000 & 0.07 & $0.02-0.22$ & 0.000 \\
\hline Very easy & 0.04 & $0.01-0.13$ & 0.000 & 0.03 & $0.01-0.99$ & 0.000 \\
\hline \multicolumn{7}{|c|}{ Municipality size (1-10,000 hab.) } \\
\hline$>10,000$ habitants & 0.50 & $0.30-0.84$ & 0.003 & 1.84 & $1.11-3.05$ & 0.018 \\
\hline
\end{tabular}

dependence in activities of daily living in the same individuals (OR $=1.84,95 \%$ CI 1.11-3.05).

\section{Discussion}

This is the first ordinal regression analysis conducted in a population-based sample exploring the properties of SOC as a predictor of both disability and dependence controlling for major socio-demographic and physical health determinants. Results indicated that individuals with a strong SOC, and particularly a high Meaningfulness score, are protected against disability, as measured by WHO-DAS II, and against dependence for both basic and instrumental ADL, as measured by the Extended Katz Index. In addition, individuals with average to high Comprehensibility were protected from self-reported disability (WHO-DAS II). These results remained consistent across the three severity levels of both outcome variables in the ordinal logistic regression models. Environmental factors were also found to be associated with disability. Easy access to social and health services was an independent protective factor reducing the risk of disability and dependence. Finally, living in urban areas was a protective factor against self-reported disability and a risk factor for dependence in activities of daily living, respectively.

A few limitations to the current analysis should be noted. First, the exclusion of participants with noncomputable SOC scores may have selected participants with less disability and higher SOC. While the SOC scores of lost participants could not be verified, the proportion of participants with moderate to extreme disability was higher among excluded participants due to noncomputable SOC (87.38 vs. $57.83 \%$ ). Moreover, a number of individuals diagnosed with dementia in the original 


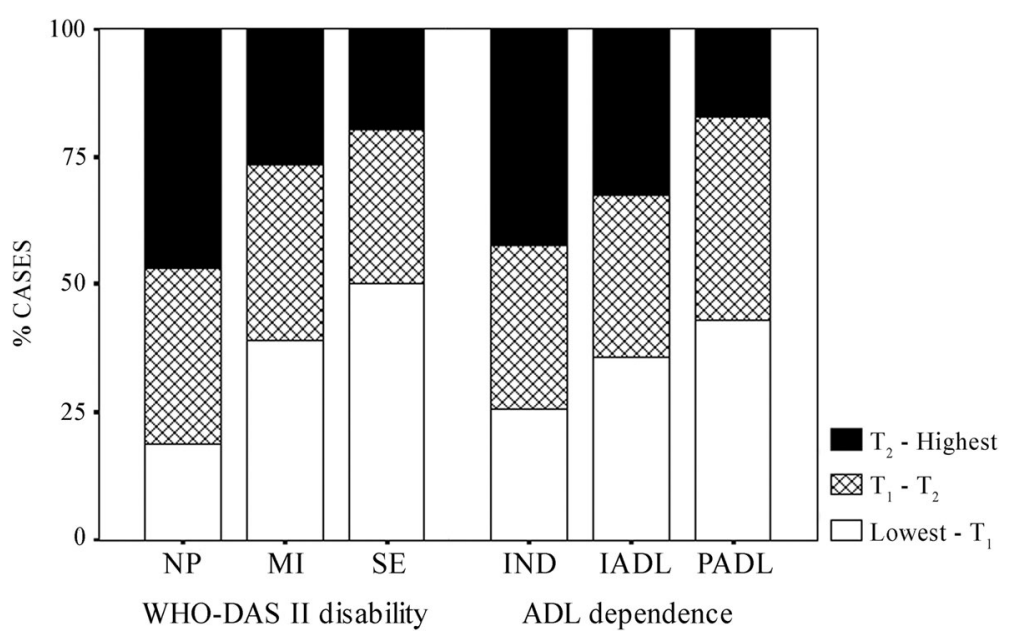

Fig. 1 Percentage of cases with low, mid and high Meaningfulness across disability and dependence levels. Notes. Comprehensibility levels established by tertiles $\left(T_{1}=\right.$ Tertil $1, T_{2}=$ Tertil, $T_{3}=$ Tertil 3). $N P=$ No problem; $M I=$ Mild problem; $S E=$ Moderate, severe or extreme problem; $\mathrm{IND}=$ Independent; $\mid \mathrm{ADL}=$ Dependent in instrumental activities; $\mathrm{PADL}=$ Dependent in basic activities

sample did not have computable SOC scores (24 out of 41). This is to be expected as higher cognitive skills are needed to complete the OLQ-13 reliably and such skills may be impaired among individuals with early stage dementia [29].

Second, unknown causes of disability co-varying with SOC may distort the ordinal regression models presented here by way of overestimating the association between target independent and dependent variables. Specifically, depression and dementia are - powerful determinants of disability in the elderly [19] and may be potential factors driving overestimation. Preliminary analyses showed that SOC was not associated with a clinical diagnosis of depression in the current dataset. In addition, our results remained unchanged by the exclusion of individuals with dementia. A more crude, yet valid approach to minimize overestimation might have been to include total comorbidity as a covariate.

In order to account for the differential pattern of findings across WHODAS 2.0 and Extended Katz Index, two differential features of these instruments should be brought to bear. First, the Extended Katz Index focuses on basic behavioral repertoires as opposed to WHO-DAS-II, which emphasizes advanced motor, cognitive and social skills. Second, the Extended Katz Index is scored objectively by a health professional and is aimed at informing the individual's need of help regardless of environmental factors (e.g., adaptations, caregiver services). By contrast, WHODAS 2.0 is a selfreported instrument focused on the self-reported difficulty in the performance of a set of activities factoring in personal and environmental factors alike. Moreover, there is evidence to suggest that self-reported versus performance-based measures of functional status and activities of daily living correlate poorly [30,31]. Thus, WHODAS 2.0 and the Extended Katz Index characterize different facets of the individual's functional status.

Our study suggests that SOC, and particularly Meaningfulness, has a protective effect against dependence and disability. This effect remained significant after controlling for sex, age, morbidity, and selected environmental and social factors. In addition, low Comprehensibility and large municipality size were risk factors for dependence. A separate analysis showed that the effect of municipality size on dependence was mainly driven by instrumental ADLs. This finding is consistent with the definition of Comprehensibility, which is associated with the complexity of the individual's environment. Therefore, Comprehensibility may be associated with the difficulties imposed by the urban environment in performing selected instrumental activities (e.g., using public transportation).

On the other hand, health and social resources were less accessible in small towns (difficult and very difficult access: $25.4 \%$ vs. $2.1 \%$ ). The fact that social resources are more readily available in the urban habitat may explain why the WHODAS 2.0 is affected differently by municipality size. Specifically, WHODAS 2.0 focuses more in social participation activities, which may have established urban residence as a protective factor for disability.

The causal pathways through which these effects operate require further empirical analysis before a more conceptually systematic interpretation of our data is possible. First, higher SOC may be highly correlated with health behaviors, which would in turn cause more favorable disability and health-related outcomes. In fact, individuals with a strong SOC demonstrate a higher adherence to 
medical treatments and rehabilitation programs and, devote more time to leisure and physical exercise [11, 32-35]. Additionally, a longitudinal study by Sulander et al. [36] showed that poor ADLs were to a considerable extent attributable to impoverished health-related habits (e.g., smoking, alcohol use, unhealthy diet and physical inactivity).

An alternative approach would be to conceptualize disability as an independent variable for SOC. Although SOC is assumed to be steady throughout adulthood [4], a few long-term longitudinal studies have shown low test-retest stability beyond the fifth year of follow-up [23]. Volanen et al. [37] reported that SOC levels were not stable over time. Specifically, individuals exposed to negative life events had lower SOC scores in inverse proportion to the recency of the negative life event. Thus, it is possible that a strong pre-existing SOC could be tempered in the face of disability of an external cause. Conversely, sense of coherence may also be malleable by favorable experiences albeit this hypothesis has seldom been evaluated. For example, Graziano et al. [38] used SOC as an intervention outcome for a brief group-based cognitive behavioral intervention for adults with multiple sclerosis. The authors reported a modest change in SOC. The trend, however, was not statistically significant. Additional intervention and longitudinal studies are needed in order to ascertain the nature of the complex intersections between SOC, environmental factors, and disability observed in the current analysis. In addition, there is a limited number of studies evaluating the predictive role of SOC among the people older than 75 . The validity of any hypotheses pertaining to the predictive or even causal roles of SOC over disability should be tested in the context of the ability of SOC to predict or cause disability should be evaluated across all phases of aging.

\section{Conclusion}

In summary, while the present study does not provide straightforward evidence of a causal connection between SOC, disability and dependence, our results suggest that individuals with low SOC, poor access to social resources, and living in rural areas may constitute a high-risk group for disability among the elderly. Our findings are consistent with the view that SOC, and particularly its Meaningfulness and Comprehensibility components, are informative behavioral factors for the assessment, rehabilitation and service planning for the elderly. These findings expand our knowledge about the complex relations between SOC and disability among older and elderly population [38].

\section{Additional file}

Additional file 1: Original Data Collection Questionnaires. (PDF $1507 \mathrm{~kb}$ )

\section{Abbreviations}

ADL: Activities of daily living; BADL: Basic activities of daily living; Cl: Confidence interval; IADL: Instrumental activities of daily living; ICF: International classification of disability; OR: Odds ratio; SOC: Sense of coherence; WHODAS 2.0: World Health Organization disability assessment schedule, $2^{\text {nd }}$ ed

\section{Acknowledgements}

The authors are indebted to the research assistants who performed fieldwork data collection. Drs. Sara Herrera and José L. Vázquez-Barquero (Hospital Universitario Marqués de Valdecilla) provided scientific advice and training. Dr. Roberto Pastor-Barriuso served as a statistical consultant. Prof. Laura Fratiglioni (Karolinska Institute) facilitated access to materials from the National Swedish Study on Aging and Care, used as the basis for some of the materials in the present study. This article is the result of a joint effort by the Spanish Epidemiological Study Group on Aging, whose members are identified below:

- National Center for Epidemiology, Carlos III Institute of Public Health,

Madrid: Javier Almazán, José Luis del Barrio, Raquel Boix, Fuencisla Avellanal, María José Medrano.

- Neurology Unit, Miguel Hernández University, General University Teaching Hospital, Alicante: Manuel Girón, Jordi Matías-Guiu, José Manuel Moltó.

- Dementia Diagnosis and Treatment Unit, Neurology Department, Bellvitge University Teaching Hospital, El Prat de Llobregat, Barcelona: Ramón Reñé. - Psychiatry Department, University of Santiago de Compostela (USC) and Psychogeriatrics Unit, Santiago de Compostela University Teaching Hospital, Santiago de Compostela, La Coruñna: Carmen García, Ramón Ramos.

- Clinical Epidemiology-Research Unit, La Paz University Teaching Hospital, Madrid. EPICARDIAN Project: Margarita Alonso, Cristina Fernández,

Rafael Gabriel.

- Dementia Unit, Santa Caterina Hospital, Gerona: Secundino López-Pousa, Jordi Llinàs-Reglà, Joan Vilalta-Franch.

- Department of Psychiatry, Granada University, Granada: Jorge Cervilla. - Neurology Department, Donostia Hospital, Bidasoa-Hondarribia Hospital, Guipúzcoa: Ana de Arce.

- Economics and Geography Institute, Scientific Research Board, Madrid: Gloria Mayoralas, Fermina Rojo.

- Department of Preventive Medicine, Madrid Autonomous University, Madrid Regional Health Authority, Madrid. Leganés Project: Ángel Otero. - Neurology Department, 12 de Octubre University Teaching Hospital, Madrid. NEDICES Project: Jaime Díaz, Rafael Gabriel, Candelas Gómez Mateos, Javier Guzmán, José Manuel Morales, Fernando Sánchez, Patricia Vale. This project, led by J. de Pedro-Cuesta, was supported by the Pfizer Foundation and by the RECSP C03-09, CIEN C03-06 and CIBERNED and CIBERSAM research networks.

\section{Funding}

This project was partially funded by a research contract in support of the project "Epidemiological Study of Dementia in Spain" signed by the Pfizer Foundation and Carlos III Institute of Health. The funding agency had no influence in the scientific process including study design, data collection, data analysis, interpretation of results, and writing of the manuscript.

\section{Availability of data and materials}

The database upon which the current analysis is based is proprietary. For specific data requests, please contact the authors.

\section{Authors' contributions}

JVO designed and conducted the analysis and produced the first draft of the manuscript. JPC made contributions to the analysis, interpretation, and writing of the study and was the PI for the overall project responsible for the survey design and coordination. IMF provided data analysis support and statistical advice. SV, MSM, PS, FR, ARL, SPH, RM, PMM, JGO, JG, FJGG, MFM, $F B J, A B, J B L$ were involved in planning and onsite data collection coordination for each of the participating sites; they also proofread the manuscript. All authors read and approved the final manuscript. 


\section{Consent for publication}

Non applicable. This manuscript does not contain any individual person's data in any form.

\section{Ethics approval and consent to participate}

The current study was approved by the Carlos III Health Institute Human Subjects Review Board (ref. no. CEl PI 4_2009), Written informed consent in accordance with the Helsinki Declaration was given by all participants.

\section{Author details}

${ }^{1}$ National Centre for Epidemiology and CIBERNED, Carlos III Institute of Health, Madrid, Spain. ${ }^{2}$ School of Psychology, The University of Auckland, Room 335B Level 3 Bldg 301 Science Centre 23 Symonds St Private Bag 92019, Auckland 1010, New Zealand. ${ }^{3}$ Arévalo Health Centre, Avila, Spain. ${ }^{4}$ Neurology Unit, Salnés Hospital, Pontevedra, Spain. ${ }^{5}$ Department of Medicine and Psychiatry, Zaragoza University, Zaragoza, Spain. ${ }^{6}$ Neurology Unit, Segovia Hospital, Segovia, Spain. ${ }^{7}$ Madrid Regional Health Authority, Madrid, Spain. ${ }^{8}$ Llodio Health Center, Day Medical Center, Oroityu-Getxo-Vizcaya, Spain. ${ }^{9}$ Psychiatry Department, University of Santiago de Compostela, Santiago de Compostela, Spain. ${ }^{10}$ Girona Biomedical Research Institute Institut d'Assistència Sanitària, Salt, Spain. ${ }^{11}$ Dementia Diagnosis and Treatment Unit, Neurology Department, Bellvitge University Teaching Hospital, Barcelona, Spain. ${ }^{12}$ Geriatrics Unit. Virgen del Valle Geriatric Hospital, Toledo, Spain. ${ }^{13}$ Neurology Unit, Virgen del Camino Hospital, Pamplona, Spain. ${ }^{14}$ Neurology Department, 12 de Octubre University Teaching Hospital and CIBERNED, Madrid, Spain. ${ }^{15}$ Department of Neurology, Hospital Universitario Donostia, San Sebastián Guipuzcoa, Spain. ${ }^{16}$ Biodonostia Research Institute, Area of Neurosciences, and CIBERNED, Carlos III Health Institute, Madrid, Spain.

Received: 2 July 2016 Accepted: 31 December 2016 Published online: 31 January 2017

\section{References}

1. Gustafsson S, Edberg AK, Johansson B, Dahlin-Ivanoff S. Multi-component health promotion and disease prevention for community-dwelling frail elderly persons: a systematic review. Eur J Ageing. 2009;6:315-29. doi:10.1007/s10433-009-0132-x.

2. Seligman ME, Steen TA, Park N, Peterson C. Positive psychology progress: empirical validation of interventions. Am Psychol. 2005:60:410-21. doi:10.1037/0003-066X.60.5.410

3. Ryff CD. Corners of myopia in the positive psychology parade. Psychol Inq 2003;14:153-9.

4. Antonovsky A. Unraveling the mystery of health: how people mange stress and stay well 1st ed. San Francisco: Jossey-Bass; 1987.

5. Eriksson M, Lindström B. Antonovsky's sense of coherence scale and the relation with health: a systematic review. J Epidemiol Community Health. 2006;60:376-81. doi:10.1136/jech.2005.041616.

6. Olsson M, Hansson K, Lundblad AM, Cederblad M. Sense of coherence: definition and explanation. International Journal of Social Welfare. 2006;15: 219-29. doi: dx.doi.org/10.1111/j.1468-2397.2006.00410.x

7. Griffiths CA. Sense of coherence and mental health rehabilitation. Clin Rehabil. 2009;23:72-8. doi:10.1177/0269215508095360.

8. Schneider G, Driesch G, Kruse A, Wachter M, Nehen HG, Heuft G. What influences self-perception of health in the elderly? The role of objective health condition, subjective well-being and sense of coherence. Arch Gerontol Geriatr. 2004;39:227-37. doi:10.1016/j.archger.2004.03.005.

9. Langius $A$, Björvell $H$. Coping ability and functional status in a Swedish population sample. Scand J Caring Sci. 1993;7:3-10.

10. Read S, Aunola K, Feldt T, Leinonen R, Ruoppila I. The Relationship Between Generalized Resistance Resources, Sense of Coherence, and Health Among Finnish People Aged 65-69. Eur Psychol. 2005;10:244-53. doi:10.1027/10169040.10.3.244

11. Widén Holmqvist L, de Pedro-Cuesta J, Holm M, Kostulas V. Intervention design for rehabilitation at home after stroke. A pilot feasibility study. Scand J Rehabil Med. 1995:27:43-50.

12. Surtees $P$, Wainwright $N$, Luben $R$, Khaw KT, Day N. Sense of coherence and mortality in men and women in the EPIC-Norfolk United Kingdom prospective cohort study. Am J Epidemiol. 2003;158:1202-9.
13. World Health Organization. World Health Organization International Classification of Functioning, Disability and Health. Geneva: World Health Organization; 2001.

14. Cieza A, Hilfiker R, Chatterji S, Kostanjsek N, Ustün BT, Stucki G. The International Classification of Functioning, Disability, and Health could be used to measure functioning. J Clin Epidemiol. 2009;62:899-911. doi:10.1016/j.jclinepi.2009.01.019.

15. de Pedro-Cuesta J, Forjaz J. [CNS diseases, disability and quality of life]. In: Martínez-Martín P, editor. Calidad de vida en neurología. Barcelona: Grupo Ars XXI de comunicación; 2006. p. 151-70.

16. Deeg DJ. Longitudinal characterization of course types of functional limitations. Disabil Rehabil. 2005;27:253-61.

17. Ustün TB, Chatterji S, Kostanjsek N, Rehm J, Kennedy C, Epping-Jordan J, et al. Developing the World Health Organization disability assessment schedule 2.0. Bull World Health Organ. 2010;88:815-23. doi:10.2471/BLT.09.067231.

18. Asberg KH, Sonn U. The cumulative structure of personal and instrumental ADL. A study of elderly people in a health service district. Scand J Rehabil Med. 1989;21:171-7.

19. Virués-Ortega J, de Pedro-Cuesta J, Vega S, Seijo-Martínez M, Saz P, Rodríguez F, et al. Prevalence and European comparison of dementia in a $>/=75$-year-old composite population in Spain. Acta Neurol Scand. 2011; 123:316-24. doi:10.1111/j.1600-0404.2010.01398.x.

20. Lobo A, Saz P, Marcos G, et al. Validation and norms of the Mini-Examen Cognoscitivo, first Spanish version of the MMSE in general geriatric population [Article in Spanish]. Med Clin. 1999;112:767-74.

21. Virués-Ortega J, de Pedro-Cuesta J, del Barrio JL, Almazán-Isla J, Bergareche A, Bermejo-Pareja F, et al. Medical, environmental and personal factors of disability in the elderly in Spain: a screening survey based on the International Classification of Functioning. Gac Sanit. 2011;25 Suppl 2:29-38. doi:10.1016/j.gaceta.2011.07.021.

22. Virués-Ortega J, de Pedro-Cuesta J, Seijo-Martínez M, Saz P, Sánchez-Sánchez F, Rojo-Pérez F, et al. Prevalence of disability in a composite $>/=75$ year-old population in Spain: a screening survey based on the International Classification of Functioning. BMC Public Health. 2011:11:176. doi:10.1186/1471-2458-11-176.

23. Eriksson M, Lindström B. Validity of Antonovsky's sense of coherence scale: a systematic review. J Epidemiol Community Health. 2005;59:460-6. doi:10.1136/jech.2003.018085.

24. Virués-Ortega J, Martínez-Martín P, del Barrio JL, Lozano LM. [Cross-cultural validation of Antonovsky's Sense of Coherence Scale (OLQ-13) in Spanish elders aged 70 years or more]. Med Clin (Barc). 2007;128:486-92.

25. Katz S, Ford AB, Moskowitz RW, Jackson BA, Jaffe MW. Studies of illness in the aged. The index of ADL: a standardized measure of biological and psychosocial function. JAMA. 1963;185:914-9.

26. Lawton MP, Brody EM. Assessment of older people: self-maintaining and instrumental activities of daily living. Gerontologist. 1969;9:179-86.

27. Spector WD, Katz S, Murphy JB, Fulton JP. The hierarchical relationship between activities of daily living and instrumental activities of daily living. J Chronic Dis. 1987;40:481-9.

28. Norekvål TM, Fridlund B, Moons P, Nordrehaug JE, Saevareid HI, Wentzel-Larsen T, Hanestad BR. Sense of coherence-a determinant of quality of life over time in older female acute myocardial infarction survivors. J Clin Nurs. 2010;19:820-31.

29. Souchay C, Moulin CJ. Memory and consciousness in Alzheimer's disease. Curr Alzheimer Res. 2009:6:186-95.

30. Agüero-Torres H, Fratiglioni L, Guo Z, Viitanen $M$, von Strauss E, Winblad B. Dementia is the major cause of functional dependence in the elderly: 3 year follow-up data from a population-based study. Am J Public Health. 1998;88:1452-6.

31. Hoeymans N, Feskens EJ, van den Bos GA, Kromhout D. Measuring functional status: cross-sectional and longitudinal associations between performance and self-report (Zutphen Elderly Study 1990-1993). J Clin Epidemiol. 1996;49:1103-10.

32. Cohen M, Kanter Y. Relation between sense of coherence and glycemic control in type 1 and type 2 diabetes. Behav Med. 2004;29:175-83. doi:10.3200/BMED.29.4.175-185.

33. Richardson CG, Ratner PA. Sense of coherence as a moderator of the effects of stressful life events on health. J Epidemiol Community Health. 2005;59: 979-84. doi:10.1136/jech.2005.036756

34. Savolainen J, Knuuttila M, Suominen-Taipale L, Martelin T, Nordblad A Niskanen $\mathrm{M}$, et al. A strong sense of coherence promotes regular dental attendance in adults. Community Dent Health. $2004 ; 21: 271-6$. 
35. Poppius E, Tenkanen L, Kalimo R, Heinsalmi P. The sense of coherence, occupation and the risk of coronary heart disease in the Helsinki Heart Study. Soc Sci Med. 1999:49:109-20.

36. Sulander T, Martelin T, Rahkonen O, Nissinen A, Uutela A. Associations of functional ability with health-related behavior and body mass index among the elderly. Arch Gerontol Geriatr. 2005;40:185-99. doi:10.1016/j.archger. 2004.08.003.

37. Volanen SM, Suominen S, Lahelma E, Koskenvuo M, Silventoinen K. Negative life events and stability of sense of coherence: a five-year follow-up study of Finnish women and men. Scand J Psychol. 2007;48:433-41. doi:10.1111/j.1467-9450.2007.00598.x.

38. Graziano F, Calandri E, Borghi M, Bonino S. The effects of a group-based cognitive behavioral therapy on people with multiple sclerosis: a randomized controlled trial. Clin Rehabil. 2014;28:264-74. doi:10.1177/ 0269215513501525.

Submit your next manuscript to BioMed Central and we will help you at every step:

- We accept pre-submission inquiries

- Our selector tool helps you to find the most relevant journal

- We provide round the clock customer support

- Convenient online submission

- Thorough peer review

- Inclusion in PubMed and all major indexing services

- Maximum visibility for your research

Submit your manuscript at www.biomedcentral.com/submit
Biomed Central 